\title{
The Difference between Male and Female Students' Self-Efficacy, Academic Engagement and Academic Achievement in Biology among Grade Ten Students in South Wollo Zone Schools in Ethiopia
}

\author{
Dr. Kulitu Hassen Mohammed \\ Wollo University, Ethiopia \\ *Prof. Harrison I. Atagana \\ Institute for Science and Technology Education, University of South Africa, Pretoria, South Africa \\ Email: atagahi@unisa.ac.za \\ Prof. Yalew Edawoke \\ Woldia University, Ethiopia.
}

Doi:10.5901/mjss.2014.v5n23p804

\begin{abstract}
The aim of this study was to examine the differences between male and female students' self-efficacy, academic engagement and academic achievement in biology among Grade 10 students in South Wollo Zone Schools in Ethiopia. In order to examine the specified aim of this study, 380 (192 male and 188 female) grade ten students were selected from two schools. Convenience sampling was used to select the schools and random sampling to select participant students. The Amharic version of the instruments adapted from "Science Self Efficacy Questionnaire (SSEQ)" and "High School Survey on Student Engagement (HSSSE, 2005) Questionnaire" were used. These questionnaires were administered during the last week of May 2012. Academic achievement test in biology was administered to collect data on students' performance score during the first week of June 2012. T-test was used to analyze quantitative data. The results of the study indicated that there was statistically significant difference between male and female students in self-efficacy and academic achievement in biology. Male students showed higher self-efficacy and academic achievement in biology than female students. There was no statistically significant difference between male and female students in academic engagement, although, there was a slight mean difference in favour of male students. The results of this study may have its own contributions to educational planners, schools administrators, teachers and parents in dealing with issues relating to the differences between male and female students' self-efficacy and academic achievement in biology. Increase in female students' self-efficacy and academic engagement could decrease the gap between male and female student academic achievement in biology. Therefore, biology teachers and educators need to factor in self-efficacy and academic engagement as useful strategies in their intervention mechanism in order to reduce the differences between male and female students' in academic achievement in biology.
\end{abstract}

Keywords: Academic achievement, academic engagement, gender, self -efficacy,

\section{Introduction}

In Ethiopia, females constitute $48.9 \%$ of the total population, which is almost half of the population (Central Statistics Authority [CSA], 2007). However, from the school age population in the country, there were $34.7 \%$ of females at secondary level (Ministry of Education Statistics Annual Abstract [MoE], 2011). Habtamu (2004) stated that inequality of education opportunity between males and females is still serious problem in Ethiopian. Mamo (2002) reported that dropout and attrition rate of female students in Ethiopia has been a serious problem in all levels of schooling. Odaga and Heneveld (1995) also indicated that in Ethiopia more females than males repeat and dropout in schools. Low participation and poor academic achievement of female students at secondary level, particularly in Grade 10 national examination, is pertinent problems that need investigation. Hadija (2002) also reported that there is a very wide gender inequality when one goes from primary to secondary and then tertiary level of education in Ethiopian schools. The gender gap in academic achievement is large in the general secondary level (Grades 9-10). The Gender Parity Index for grades 9-10 student was 0.71 in 2011. This showed that much remains to be done in reducing the difference between male and female students' academic achievement (MoE, 2011). Gender Parity Index is the ratio of female to male Gross Enrolment 
Rate. Not only females are low in number but are also poorly performing at this level with particular reference to Grade 10 national examination (MoE, 2011).

Table.1.1 percentage of students who achieved passing grade in Grade 10 national examination in Ethiopia for the last six years

\begin{tabular}{|c|c|c|c|}
\hline Year & Males (\%) & Females (\%) & Both (\%) \\
\hline 2005 & 50.3 & 29.1 & 42.8 \\
\hline 2006 & 54.7 & 36.9 & 48.8 \\
\hline 2007 & 56.1 & 39.5 & 49.3 \\
\hline 2008 & 56.1 & 39.3 & 49.8 \\
\hline 2009 & 44.6 & 28.6 & 38.4 \\
\hline 2010 & 49.9 & 32.2 & 42.6 \\
\hline
\end{tabular}

Source: Ethiopian Ministry of Education Statistics Annual Abstract, 2011

For example, a national learning assessment carried out from 2005-2010 in Grade 10 students showed that female students' academic performance was lower than males in average (MoE, 2011). One can see the gap between male and female students' in getting passing grade from Table 1.1.

Regarding the difference between male and female students academic achievement in Ethiopia, some researchers have argued that socio-economic status, socio-cultural beliefs, unfavorable school environment, political and institutional conditions can affect female student academic achievement. For example, the financial and moral support provided to females for schooling is limited as compared to males (Teshome, 2003). MoE (2004) stated that learning environment is a determining factor for female students' performance and survival at any given educational level. Odaga and Heneveld (1995) argue that the school environment, teachers' attitude and pedagogy, and gender bias in learning materials affects the performance and attainment of female students in schools. Adetunde \&Akesina (2008) and MoE (2004) have argued that families tend to influence the upbringing of their daughters based on the cultural values and religious norms. At early age, females are taught to be quiet shy and most importantly obedient, hence, they could not express themselves and interact with teachers and students in class. Females are encouraged to get married and establish families at a very early age. In fact, early marriage and abduction are the major cultural problems hindering females' schooling in Ethiopia because in most ethnic cultures in Ethiopia, males are considered as more important than females. The values justified this idea saying that males are the breadwinners, therefore; they should get all privileges and treatments. Females exist to please males thus females should be dependent on males for everything especially in their identities and social definitions (Taddesse, 2009).

However, it may be also reasonable to assume that differences between male and female students' in academic achievement could be explained by students' personal characteristics such as self-efficacy and academic engagement. This belief is supported by a small but steadily growing body of research. Some previous researchers examined the difference between male and female students in self- efficacy and academic engagement in different levels.

Students' self-efficacy was found to be important predictors of students' academic achievement by previous researches. For example, (Sakiz, 2011; Vuong, Brown-Welty, \& Tracz, 2010; Nasiriyan, Khezri Azar, Noruzy, \& Dalvand, 2011) have found that self-efficacy had a significant and positive effect on academic achievement. Britner \& Pajares (2006) also found that self-efficacy was best predictor of physics conceptual understanding as well as physics grade. Students with high self-efficacy tend to choose more challenging tasks, show more effort, and do not give up easily, which explains why students of similar ability can have different academic performance (Pajares 1997). Students who have a strong belief that they can succeed in chemistry-related tasks and activities will be more likely to select such tasks and activities, and work hard to complete them successfully (Britner \& Pajares, 2006).

Academic engagement was also found to be important predictors of students' academic achievement by previous researches. For example, Fredricks, et al. (2004) suggested that the concept of academic engagement and its link to student achievement may provide a new perspective from which to examine student achievement. Because student academic disengagement is one of the problems of schools as a low level of academic engagement has negative effects on academic achievement. Academic engagement plays a significant role in students' academic achievement (Ogbu \& Davis, 2003; Stewart, 2007). Such engagement can be described as the level of commitment and involvement and the amount of time, energy and effort that students put into their educational learning activities (Stewart, 2007). Adolescent student's engagement in academic activities has a significant effect on academic achievement. Students with higher 
academic engagement tend to have higher academic performance (Carbonaro, 2005; Stewart 2007; Sirin, 2005; Flowers \& Flowers, 2008; Wang \& Holcombe, 2010). Academically Engaged students are more likely to earn better grades and perform well on standardized tests (Fredricks, et al., 2004 \& Marks 2000).

In Ethiopian context, despite the significance of the problem and students' self efficacy and academic engagement were found to be important predictors of students' academic achievement by many previous researches in other countries, in different levels and disciplines, no emphasis has been given to students' self-efficacy and academic engagement in an attempt to alleviate the differences between male and female students' academic achievement. Therefore, this study intends to examine the difference between male and female student in self-efficacy, academic engagement and academic achievement in biology among Grade 10 students in South Wollo Zone Schools in Ethiopia. It is believed that the result of this study can contribute for those who are responsible and interested in alleviating the difference between male and female students in self-efficacy, academic engagement and academic achievement. For example, teachers, parents, educational planners and local and international non-governmental organizations educational planners who engaged in the formulation of sector oriented strategic plans in the areas of education could utilize the results of this study, particularly in Ethiopia.

\subsection{Aims}

The aim of this study was to examine the difference between male and female students' in self-efficacy, academic engagement and academic achievement in biology among Grade 10 students in South Wollo Schools in Ethiopia.

\subsection{Research Questions}

1. Is there a statistically significant difference between male and female students' self-efficacy in biology?

2. Is there a statistically significant difference between male and female students' academic engagement in biology?

3. Is there a statistically significant difference between male and female students' academic achievement in biology?

\subsection{Null Hypotheses}

Null Hypothesis 1: There is no a statistically significant difference between male and female students' self-efficacy in biology.

Null Hypothesis 2: There is no a statistically significant difference between male and female students' academic engagement in biology.

Null Hypothesis 3: There is no a statistically significant difference between male and female students' academic achievement in biology.

\section{Literature Review}

In gender theory, a distinction is made between sex and gender (Glasser \& Smith, 2008). It is argued that certain traits vary significantly among persons of the same sex, and that gender is socially constructed rather than primarily being connected to biological traits. "The term gender holds promise for studies of the norms and expectations that influence people's behaviors in social contexts including school classrooms" (Glasser \& Smith, 2008, p.349). Hence, it may be more informative to focus on the notion of gender. However, to reduce the complexity of the research design in this study, it is more appropriate to use the terms male and female students rather than sex or gender. It is argued that reviewing the existing condition, focusing on male and female students is still valuable and important because the aim of this study is to examine the difference between male and female students in self efficacy, academic engagement and achievement in biology as a result of both biological and social factors.

\subsection{The Difference between Male and Female Students in Academic Achievement}

Previous researches on the difference between female and male students' in academic achievement in education revealed some differences on how males and females learn and achieve academically(Chee, Pino, \& Smith, 2005; Sheard, 2009; Dayıoglu \& Türüt- Asık, 2004). For example, Chee, Pino, \& Smith, (2005) and Dayıoglu \& Türüt- Asık 
(2004) have found significant sex differences in academic achievement, as measured by Cumulative Grade-PointAverage. Female students had significantly higher academic achievement than males in different higher education levels. These findings have also been supported by some studies conducted in high school students (Steinmayr \& Spinath, 2008). Some researchers have explained the reasons why female students exceed their male counterparts in academic performance by saying that female students have higher academic ethics, academic motivation and readily engage with academic goals and activities than males (Chee, Pino, \& Smith, 2005).

On the other hand, Ajiboye and Tella (2006) have found that male students had significantly higher scores on social studies course when compared to their female compartments in University of Botswana. In addition, National Organization for Examination $(2004,2008)$ reported that females' academic achievement is significantly lower than males in primary and secondary education in Ethiopia. Tamirie, (2009) reported that females' academic achievement is significantly lower than males in science in Minilik II secondary school in Addis Ababa. Odaga \& Heneveld (1995) also indicated that in Ethiopia there was low academic achievement of female students at secondary level, particularly in grade ten national examinations. The Education and Training Policy (TGE, 1994) states also from the school age population of female students in the country, there was very low proportion of female students when compared to males at secondary level. Not only females are low in number but also poorly performing at the school with particular reference to grade ten national examination.

\subsection{The Difference between Male and Female Students in Self-Efficacy}

Some studies have reported significant differences in self-efficacy between male and female students' (Vogt, Hocevar, \& Hagedorn, 2007; Sakiz, 2011 \&Vuong, Brown-Welty, \& Tracz, 2010). For example, Lent et al. (2005) and Vogt, Hocevar, \& Hagedorn (2007) have reported that male students have significantly higher self-efficacy than females. On the other hand, there are studies which did not find significant male and female students' differences in self-efficacy. For example, Vuong, Brown-Welty, and Tracz (2010) have examined the effects of self-efficacy on academic success of firstgeneration college sophomore students and did not find significant effect of self-efficacy on male and female students. Similarly, a study conducted in higher education institutions by Clutts (2010) indicated non-significant male and female students' differences in academic self-efficacy.

\subsection{The Difference between Male and Female Students' in Academic Engagement}

Jones, Howe and Rua (2000) argued that there remains a gender difference in science experience, attitudes and perceptions of science courses. Jones et al. (2000) also found males were more likely to have extracurricular experience than girls with science-related artifacts (such as microscopes) and were more likely to endorse interest in science-related hobbies. Miller (2006) has found that females simply do not find science interesting or relevant to their life goals and in fact, their dislike to science is not linked to a perception that it is too hard or not fitting. Brotman and Moore (2008) have revealed that females are typically more concerned about life science than more abstract scientific principles, experiments while they were much less interested in laboratory based sciences, physical science and engineering subjects because they cannot make affective links between those subjects and what they care about.

\section{Methodology}

\subsection{Participants}

A total of three hundred and eighty (188 female and 192 male) students in the age range of 14-19 years were selected from two secondary schools using random sampling method.

\subsection{Data collecting instruments}

Self-efficacy and Academic Engagement Instruments: The assessment instruments used in this study were the "biology self-efficacy sub-questionnaire" (SSEQ) prepared by (Smith, 1992) and "the High School Survey on Student Engagement "(HSSSE, 2005) developed by the Indiana University School of Education. Both of the instruments were adapted and translated into Amharic version and rated on a 5-point Likert scale.

Biology Achievement Measure: students' biology examination score was used as the academic achievement indicator in biology. Twenty five multiple choice questions was prepared by the researcher with consultation of biology 
teachers from sample school who are currently teaching biology for grade ten students to ensure content validity of the questions

\subsection{Validity and Reliability}

Validity of all measures was explored by subjecting the items to professionals in biology education and psychology as well as grade ten biology teachers. These professionals reviewed the instruments by assessing the ability of items to accurately represent common theory and practice and assessed the usability of the instrument, the clarity of the items, readability of the questions, etc. Feedback obtained from the professionals was used to revise the instruments. A pilot study was done on forty respondents (20 females and 20 males) of tenth grade students to determine the internal consistency reliability coefficients of the Amharic version of the instruments. The internal consistency reliability coefficients were .718 for self efficacy, .909 for the academic engagement and .787 academic achievements in biology.

\subsection{Data Collecting Methods and Procedures}

Data were collected via self report questionnaires from Grade 10 students and assesses their perceptions at a given time. Written permission was asked from participants to conduct this study prior to beginning the research. Once permission is granted the researcher was visited schools to conduct the research. At the schools the purpose of the research was explained and requested permission to meet the students for the purpose of collecting data. Then the participants were told that they can participate or drop out at any point during the investigation, if they so wish. They were also informed that the result of the study are confidential and will not affect their grades. Anybody willing to participate after all this explanation is presumed to have give informed consent to the researcher to involve in the investigation. Finally, the instruments were group administered in the participants' biology classes. Copies of the Amharic version questionnaires were administered for each sample respondents.

\subsection{Data Analysis}

The data obtained from administration of the measuring instruments were analyzed by using descriptive and inferential statistics were used to examine the difference between male and female students in variables of this study.

\section{Results}

\subsection{Descriptive Statistics}

Table 4.1. Descriptive statistics of male and female students' self-efficacy in biology

\begin{tabular}{|l|c|c|c|}
\hline Sex & Mean & N & Std. Deviation \\
\hline Male & 20.9427 & 192 & 4.74610 \\
Female & 18.7872 & 188 & 4.27872 \\
Total & 19.8763 & 380 & 4.64212 \\
\hline
\end{tabular}

Self-efficacy scores were categorized according to students' sex as presented in Table 4.1. The scores could range from 6 to 30 in which higher scores means that students were confident they can learn and understand the material being taught in the biology class and perform well. The mean score for male students was 20.94 and $18.78 \mathrm{f}$ or females. Male students had higher mean score in self- efficacy than that of females'.

Table.4.2. Descriptive statistics male and female students' academic engagement in biology

\begin{tabular}{|l|c|c|c|}
\hline Sex & Mean & N & Std. Deviation \\
\hline Male & 226.07 & 192 & 45.59646 \\
Female & 220.38 & 188 & 45.50467 \\
Total & 223.25 & 380 & 45.58004 \\
\hline
\end{tabular}


Academic engagement score was also categorized according to sex of students' as indicated in Table 4.2. The mean scores in academic engagement for males were 226.07 while 220.38 for females. That means male students had slightly higher mean score than female students

Table 4.3. Descriptive statistics of male and female students' academic achievement in biology

\begin{tabular}{|l|c|c|c|}
\hline Sex & Mean & N & Std. Deviation \\
\hline Male & 42.1042 & 192 & 13.89827 \\
Female & 32.1702 & 188 & 11.40845 \\
Total & 37.1895 & 380 & 13.64905 \\
\hline
\end{tabular}

Academic achievement in biology scores were categorized according to students' sex as Table 4.3 indicated. Male students had a mean score of 42.10 while females had a mean of 32.17 , which means that male students' academic achievement in biology was higher than female students'.

\subsection{Inferential Statistics}

Testing Null Hypotheses 1: There is no a statistically significant difference between male and female students' self efficacy in biology

Table 4.4. Difference between male and female students' in self-efficacy

\begin{tabular}{|l|c|c|c|c|}
\hline SEB & $\mathrm{N}$ & Mean & t-value & Sig. (2-tailed) \\
\hline Females & 188 & 18.78 & 4.647 & .000 \\
Males & 192 & 20.94 & & \\
\hline
\end{tabular}

The results of independent t-test showed that there is a statistically significant difference between male and female students' in biology self-efficacy as seen in Table 4.4. The null hypothesis that stated, there is no a statistically significant difference between male and female students' self-efficacy in biology was rejected at $T=4.647, p=.0 .000$. In other words, there is a statistically significant difference between male and female students' biology self-efficacy

Testing Null Hypotheses 2: There is no a statistically significant difference between male and female students' academic engagement in biology

Table 4.5. Difference between male and female students' in academic engagement

\begin{tabular}{|l|c|c|c|c|}
\hline AEB & $\mathrm{N}$ & Mean & t-value & Sig. (2-tailed) \\
\hline Females & 188 & 220.38 & -2.11 & .833 \\
Males & 192 & 226.07 & & \\
\hline
\end{tabular}

There was a statistically significant difference between male and female students' academic engagement as Table 4.5 indicated. The null hypothesis that stated, there is no a statistical significant difference between male and female students' academic engagement in biology was not rejected. Because $T=-2.11, p=0.833$. That means, there is no a statistically significant difference between male and female students' academic engagement in biology

Testing Null Hypotheses 3: There is no a statistically significant difference between male and female students' academic achievement in biology

Table 4.6. Difference between male and female students' academic achievement in biology

\begin{tabular}{|l|c|c|c|c|}
\hline $\mathrm{AAB}$ & $\mathrm{N}$ & Mean & t-value & Sig. (2-tailed) \\
\hline Females & 188 & 32.1702 & 6.607 & .000 \\
Males & 192 & 42.1042 & & \\
\hline
\end{tabular}


There was a statistically significant difference between male and female students' academic achievement in biology score as Table 4.6 showed. The null hypothesis that stated, there is no a statistically significant difference between male and female students' academic achievement in biology score was rejected at $T=7.607, p=.000$. In other words, there is a statistically significant difference between male and female students' academic achievement in biology

\section{Discussions}

The purpose of this study was to examine the difference between male and female students' self-efficacy, academic engagement and academic achievement in biology among Grade 10 students in South Wollo Schools in Ethiopia. Then, it would be suggested strategies that may help educational planers, school administrator, biology teachers and parents to boost female students' academic achievements in biology and alleviate the difference between male and female students. Because, in Ethiopian context, despite the significance of the problem, there is lack of research findings in differences between male and female students' in self-efficacy and academic engagement and academic achievement in biology.

Some previous researchers examined the difference between male and female students in academic achievement.

For example, Odaga and Heneveld (1995) argued that family's socio-economic status influences the daughter's academic performance. MoE (2004) indicated that families tend to influence the upbringing of their daughters based on the cultural values and religious norms. At early age females are taught to be quiet shy and most importantly obedient, hence, their inability to express themselves and interact with teachers and students in class make them isolated. Financial and moral support provided to females for schooling is limited as compared to males (Teshome, 2003). Adetunde and Akesina (2008) argued that families tend to influence the upbringing of their daughters based on the cultural values and religious norms. At early age, females are taught to be quiet shy and most importantly obedient, hence, they could not express themselves and interact with teachers and students in class. The cultural values in Ethiopia justified this idea by saying that males are the breadwinner and therefore they should get all privileges and treatments (Taddesse, 2009).

It is important to realize that low societal and parental expectations and negative attitudes can take the form of stereotype threat (McJunkin, 2009) in females and can also affect females' confidence that they have ability to be successful and perform better than males. However, it may be also reasonable to assume that differences between male and female students' in academic achievement could be explained by students' personal characteristics such as selfefficacy and academic engagement. Therefore, this study intends to examine the difference between male and female student in self-efficacy, academic engagement and academic achievement in biology among Grade 10 students in South Wollo Zone Schools in Ethiopia.

The results of this study revealed that the mean score for male students was 42.10 while females had a mean of 32.17 for academic achievement in biology, which means that male students' academic achievement in biology was higher than females'. There was also a statistically significant difference between male and female students' academic achievement in biology score $(T=7.607, p=.000)$. Although male students had high mean a score than females in academic achievement in biology, both male and female students had mean scores below the minimum required standard set by Ethiopian Ministry of Education to pass from one grade level to the next, which is 50\%.

One of the explanations for low academic achievement of female students in biology in this study could be due to low self-efficacy of females in biology. Descriptive statistics results of this study indicated that the mean self-efficacy score for male students was 20.94 and $18.78 \mathrm{f}$ or females. Male students had higher mean score in self- efficacy than those females in biology. The result of the independent t-test has also revealed that there was a significant difference between female and male students in their self-efficacy in biology which is $(T=4.647, p=.0 .000)$. Because, in Ethiopian cultural context the society and parents have low expectations and negative attitudes towards females' academic success in which males receive more attention and encouragement than females to perform effectively in academic endeavors.

The results of this study revealed also that there was a slight mean difference that favors males, but the results of independent t-test showed that there is no a statistically significant difference between male and female students' academic engagement in biology which is $(T=-2.11, p=0$.833). However, it is not possible to declare that females are equal in academic engagement in biology with their male compartments. Therefore, the other explanations for low academic achievement of female students in biology in this study could be due to low academic engagement females in biology

The probable explanations for non significant difference between male and female students' academic engagement in biology is the tutorials, workshops and trainings given to female students to improve their involvement and participation in schools (TGE, 1994) as indicted in Education Sector Development Program (1998-2003). These supports 
may have had positive influence on improving female students' academic engagement and contributed to reducing the difference between male and female students' academic engagement in biology in this study.

\section{Limitations}

Although the results of this study provided support for the proposed hypotheses, certain limitations should be acknowledged and kept in mind when interpreting the results. As in any research study, several considerations may affect the overall results, effectiveness and usefulness of the results of this study. It is also important to note that the perceptions Grade 10 students on their own self-efficacy and academic engagement may differ from their actual academic self-efficacy and academic engagement. In addition, there is the danger that students may not honestly answer the questions. One potential problem of self-report assessment might bring about concerns of validity is the extent to which individuals can objectively rate their own behavior, feelings and abilities. According to (DeAngelis 2003) "knowing thyself isn't easy" and people have a tendency to overrate their abilities. She added that there are certain reasons why it is hard for people to know themselves, especially in a subjective area like intelligence. People tend to perceive their competence in self-serving ways. To minimize this problem, students were assured that their responses would remain confidential and that only aggregate data would be reported.

It must be acknowledged that there can be several other factors, which are likely to affect the academic achievement of female students because of the complex nature of academic achievement. Therefore, it would be important to include some of these factors as predictor of academic achievement. For example, it is important to consider attitudes towards learning in future research because, as (Bakar, Tarmizi, Mahyuddin, Elias, Luan, \& Ayub, 2010) reported, attitudes towards learning play a crucial role in affecting the academic achievement of students. It is also important to examine the academic self-concept of students because, as reported by (Choi, 2005; Cokley \& Patel, 2007), academic self-concept is significantly and positively related to the academic achievement of students.

Finally, this study has been limited to grade ten students recruited only from two general secondary schools found in South Wollo Zone in Ethiopia. So, the findings cannot be generalized to the students from the other schools. Future research could involve large number of general secondary schools in Ethiopia.

\section{Implications}

Despite the aforementioned limitations, the results of this study can have its own implications for educational planners, schools administrators, teachers and parents. It helps them to realize that raising female students 'self-efficacy and academic engagement can play a significant role in lifting up female students' academic achievement in biology.

For example, it can help biology teachers in considering that self-efficacy and academic engagement as important and valuable issues in raising female students' academic achievement in biology and take efforts to raise any low level of self-efficacy and academic engagement. It helps them also to be aware of any unintentionally negative influences they may be exerting on female student self-efficacy and academic engagement because just as self-efficacy and academic engagement can be raised, they can be also lowered. In addition, it helps educational planners and school administrators to design strategies for raising female students self-efficacy, academic engagement academic achievement in biology particularly, for those who are working in South Wollo Zone in Ethiopia. It can help also parents to stress in the importance and value of self-efficacy and academic engagement in raising their daughter's academic achievement in biology and encourage their daughter's to preserve in the face of academic and social barriers regarding their academic success at home.

\section{Conclusion}

Based on the results of this study, it could be concluded that male students had higher self-efficacy and academic achievement in biology than females. Male students had also slightly high mean score than females' in academic engagement, although, it was not statistically significant. Therefore, it is necessary for educational planners, school administrators, parents and biology teachers to be aware that self-efficacy and academic engagement can contribute for the difference between male and female students in academic achievement in biology. Parents and teachers need to change their negative attitudes towards female students' participations and academic success (Adetunde \&Akesina, 2008\& MoE, 2004). They required considering that self-efficacy and academic engagement as important and valuable issues in raising female students' academic achievement in biology and take efforts to raise any low level of self-efficacy and academic engagement. They need also to be aware of any unintentionally negative influences they may be exerting 
on female student self-efficacy and academic engagement because just as self-efficacy and academic engagement can be raised, they can be also lowered. Educational planners need to support school administrators in creating a school climate dedicated to enhance female students' self-efficacy and academic engagement and provide staff development trainings for biology teachers on how to raise female students' self-efficacy, academic engagement' and academic achievement. It can help them to alleviate the difference between male and female students in academic achievement in biology.

\section{Recommendations for Further Research}

Future research can examine male and female students' differences in self-efficacy and academic engagement in other science subjects such as chemistry, physics etc. Future research can be perform a replication of this study for different grade levels and various geographic locations in Ethiopia and elsewhere to see if the results are similar.

\section{References}

Adetunde, I.A. and A.P. Akensina ,(2008). Factors Affecting the Standard of Female Education: A Case study of senior Secondary Schools. Journal of Social Sciences 4(4):338-342.

Ajiboye, J. O., \&Tella, A. (2006). Class attendance and gender effects on undergraduate students" achievement in a social studies course in Botswana. Essays in Education, 18, 1-11.

Bakar, K. A., Tarmizi, R. A., Mahyuddin, R., Elias, H., Luan, W. S., \& Ayub, A. F. M. (2010). Relationships between university students" achievement motivation, attitude and academic performance in Malaysia. Procedia Social and Behavioral Sciences, 2,49064910.

Brotman JS, Moore FM., (2008) Girls and science: a review of four themes in the science education literature. J Res Sci Teach 45(9):971-1002.

Burkham DT, Lee VE, Smerdon BA., (1997) Gender and science learning early in high school: subject matter and laboratory experiences. Am Educ Res J 34(2):297-331.

Central Statistical Agency (2008). Summary and statistical report of the 2007 population and housing census results. Addis Ababa, Ethiopia.

Chee, K. H., Pino, N. W., \& Smith, W. L. (2005). Gender differences in the academic ethic and academic achievement. College Student Journal, 39, 604-618.

Choi, N.(2005).Self-efficacy and self-concept as predictors of college students' academic performance. Psychology in the Schools, 42(2), 197-205.

Clutts, D. W. (2010). Mathematics self-efficacy of community college students in developmental mathematics courses. Unpublished Doctoral Dissertation, Liberty University, Lynchburg,Virginia. Retrieved from http://digital commons.liberty.edu/cgi/ view content.cgi? article=1416\& context=doctoral on 20/09/2011.

Dalgety,J.,Coll,R.,\& Jones,A.(2003).Development of Chemistry Attitudes and Experiences Questionnaire (CAEQ). Journal of Research in Science Teaching, 40(7), 649-668.Education, 31, 303-328.

Dayıoglu, M., \& Türüt-Asık, S.(2004). Gender differences in academic performance in a large public university in Turkey. ERC Working Papers in Economics 04/17. Retrieved from http://www. erc.metu.edu.tr/menu/series04/0417.pdf on 20/04/2011.

DeAngelis, T.(2003). Why we overestimate our competence. APA Online, 34(2), Available online http://www.apa.org/monitor/feb03/ overestimate.html. Retrieved September 14, 2003.

DeBacker, T. K., \& Nelson, R. M.(2000). Motivation to learn science: Differences related to gender, class type, and ability. Journal of Educational Research, 93(4), 245- 255.

Fredricks, JA, Blumenfeld, PC, \& Paris, AH., (2004). School Engagement: Potential of the Concept, State of the Evidence. Review of Educational Research, 74, 59-109.

Glick, P., (2008). What Policies will Reduce Gender Schooling Gaps in Developing Countries: Evidence and Interpretation? World Development 36 (9):1623 - 1624.

Glasser, H.M. and J.P. Smith, (2008) 'On the Vague Meaning of 'Gender' in Education Research: The Problem, Its Sources, and Recommendations for Practice', Educational Researcher, vol. 37, No. 6, pp.343-350.

Habtamu, W.,(2004). Gender and Regional Disparities in Opportunities to Higher Education in Ethiopia: Challenges for the Promotion of Social justice. The Ethiopian Journal of Education: 1(2):1- 39.

Hadija, M.,(2002). Enrolment and Academic Performance of Female Students in Higher learning Institutions: A Case Study. 9 (2) : 9 16. IER FLAMBEAU. women? Washington, DC: Association of American Colleges.

Hampton, N. Z., \& Mason, E., (2003). Learning disabilities, gender, sources of self-efficacy beliefs, and academic achievement in high school students. Journal of School Psychology, 41, 101-112.

High School Survey on Student Engagement, 2005). Indiana University, "What We Can Learn from High School Students" IN: (Bloomington, [Retrieved July 21st, 2006 fromwww.iub.edu/ nsse/ hssse/pdf/hssse_2005_report.pdf] Institute for Research and Reform in Education.

Linnenbrink, E.A., \& Pintrich, P.R. (2003).The role of self-efficacy beliefs in student engagement and learning in the classroom. Reading 
\& Writing Quarterly: Overcoming Learning Difficulties,19,119-137.

Mamo, M. (2002). Factors Affecting the Academic Achievement of Female Students in Ethiopia. A case of Alemaya University". Ethiopia, Addis Ababa, AAU.

Marks, H. M.,(2000). "Student Engagement in Instructional Activity: Patterns in the Elementary, Middle, and High School Years," American Educational Research Journal, 37, (1) 153-84.

Martin, A. J., (2003). Enhancing the educational outcomes of boys: Findings from the A.C.T. investigation into boys' education. Youth Studies Australia, 22, 27-36. Downloaded from http://rer. aera.net at Universitaetsbibliothek on February 25, 2010.

McJunkin, L. M. (2009). Effects of stereotype threat on undergraduate women's' math performance: Participant pool vs. classroom situations. Emporia State Research Studies, 45(2), 27-31.

Ministry of Education, (2004). "A Study of Gender Gap in Enrolment, Retention and Performance in primary Schools of Regions". Addis Ababa. WAD.

Ministry of Education (2005) Consolidated National Performance Report 2003/2004.Addis Ababa: Ministry of Education, Ethiopia.

Ministry of Education, (2007). 'General Education Quality Improvement Program (2008/09-2012/13) Program Document', Federal Democratic Republic of Ethiopia, Addis Ababa, Ethiopia, (Unpublished).

Ministry of Education,(2009). Harmonized curriculum for Bachelor's Degree program in Ethiopia. Addis Ababa.

Ministry of Education. (2011). Education statistics annual abstract 2003 E.C. (2010/2011). Addis Ababa, Ethiopia.

Ministry of Education (2005). Education Sector Development Program III (ESDP-III): Program Action Plan. Addis Ababa.

Odaga, A. and W. Heneveld, (1995). Girls Schools in Sub-Saharan Africa. Washington, D.C. The World Bank.

Oxfam, (2005). Girls' Education in Africa: Education and Gender Equality Series, Program Insight. December 2005.

Pajares, F., \& Valiante, G. (2001). Gender differences in writing motivation and achievement of middle school students: A function of gender orientation? Contemporary Educational Psychology, 24, 366-381.

Pajares, F., (2002).Overview of social cognitive theory and of self-efficacy. Retrieved March 31, 2009 \ from http://www.emory.edu/ EDUCATION/mfp/eff.html.

Pintrich, P. R., \& DeGroot, E. V., (1990). Motivational and self-regulated learning components of classroom academic performance. Journal of Educational Psychology, 82(1), 33-40.

Reynolds, A. L., \& Weigand, M. J. (2010). The relationships among academic attitudes, psychological attitudes, and the first-semester academic achievement of first year college students. Journal of Student Affairs Research and Practice, 47(2),175-195.

Sakiz, G. (2011). Mastery and performance approach goal orientations in relation to academic self- efficacy beliefs and academic help seeking behaviors of college students in Turkey. Educational Research, 2(1), 771-778.

Sheard, M. (2009). Hardiness commitment, gender, and age differentiate university academic performance. British Journal of Educational Psychology, 79, 189- 204.

Smith, J. M., (1992).Science Self-efficacy Questionnaire. (Report No. SE054247). Massachusetts. (ERIC Document Reproduction Service No. ED368558).

Steinmayr, R., \& Spinath, B. (2008). Sex differences in school achievement: What are the roles of personality and achievement motivation? European Journal of Personality, 22, 185-209.

Tadesse, S. (2009). Understanding Female Students' Academic Performance: An Exploration of the

Situation in South Nations Nationalities and Peoples Regional State - Ethiopia. Published Masters' thesis, The Hague, The Netherlands, November, 2009.

Tamirie, A. (2009). Trend analysis of males' and females' education in different school levels and school types in Addis Ababa., Proceedings of the 16th International Conference of Ethiopian Studies, Trondheim.

Teshome Nekatibeb,(2003). Gender Disparity in Ethiopian Primary Education: Ethiopia: Addis Ababa, UNICEF.

Transitional Government of Ethiopia, (1994) Education and Training Policy. Addis Ababa: Ministry of Education, Ethiopia.

Turner, E. A., \& Heffer, R. W. (2005). Parental influences on academic performance and attitudes toward achievement. Retrieved from http://psychology.tamu.edu/posters/earlturner2005.pdf on 03/09/2008.

Vogt, C. M., Hocevar, D., \& Hagedorn, L. S. (2007). A Social cognitive construct validation: Determining women's and men's success in engineering programs. The Journal of Higher Education, 78(3), 337-64.

Vuong, M., Brown-Welty, S., \& Tracz, S. (2010).The effects of self-efficacy on academic success of first generation college sophomore students. Journal of College Student Development, 51(1), 50-64.

Yalew, E. (1997). Self-efficacy, perceived importance, attitudes, and achievement in physics among Tana Haik Comprehensive Secondary School male and female students: A path analysis. The Ethiopian Journal of Education, 17(1), 29-49. 